\title{
Comparison of Antibacterial and Immunological Properties of Mesenchymal Stem/Stromal Cells from Equine Bone Marrow, Endometrium, and Adipose Tissue
}

\author{
Yennifer Cortés-Araya, ${ }^{1, *}$ Karin Amilon,, ${ }^{1, *}$ Burgunde Elisabeth Rink, ${ }^{1}$ Georgina Black, \\ Zofia Lisowski, Francesc Xavier Donadeu, ${ }^{1,2}$ and Cristina L. Esteves ${ }^{1}$
}

Equine mesenchymal stem/stromal cells (MSCs) are multipotent cells that are widely used for treatment of musculoskeletal injuries, and there is significant interest in expanding their application to nonorthopedic conditions. MSCs possess antibacterial and immunomodulatory properties that may be relevant for combating infection; however, comparative studies using MSCs from different origins have not been carried out in the horse, and this was the focus of this study. Our results showed that MSC-conditioned media attenuated the growth of Escherichia coli, and that this effect was, on average, more pronounced for endometrium (EM)-derived and adipose tissue (AT)-derived MSCs than for bone marrow (BM)-derived MSCs. In addition, the antimicrobial lipocalin-2 was expressed at mean higher levels in EM-MSCs than in AT-MSCs and BM-MSCs, and the bacterial component lipopolysaccharide (LPS) stimulated its production by all three MSC types. We also showed that MSCs express interleukin-6 (IL-6), IL-8, monocyte chemoattractant protein-1, chemokine ligand-5, and Toll-like receptor 4, and that, in general, these cytokines were induced in all cell types by LPS. Low expression levels of the macrophage marker colony-stimulating factor 1 receptor were detected in BM-MSCs and EM-MSCs but not in AT-MSCs. Altogether, these findings suggest that equine MSCs from EM, AT, and BM have both direct and indirect antimicrobial properties that may vary between MSCs from different origins and could be exploited toward improvement of regenerative therapies for horses.

Keywords: mesenchymal stem/stromal cells, veterinary, horse, adipose tissue, endometrium, bacteria

\section{Introduction}

E QUINE MESENChyMal STEM/STROMAL cells (MSCs), obtained typically from bone marrow (BM) and adipose tissue (AT), have been used clinically for more than a decade. Although great progress has been made toward their characterization [1-9], there is still a lack of understanding regarding their antibacterial and immune-related properties. Antibiotic resistance is emerging as a major health risk for both humans and animals, and new strategies to ameliorate this problem are in great need.

The regenerative potential of MSCs derives not only from their ability to differentiate into mature mesenchymal cell lineages, but also from a variety of immunomodulatory effects exerted by these cells [10-14] that, importantly, contribute to combating infection and determine clinical outcome in patients receiving MSCs. Moreover, human and mouse MSCs have been shown to express several antimi- crobials and to be able to attenuate bacterial growth $[12,15-$ 17], a finding that has been recently extended to MSCs derived from equine blood [18].

In humans, MSCs can have different inflammatory phenotypes depending on the extracellular milieu [19]. Interestingly, in a low inflammatory environment or upon activation of Toll-like receptor 4 (TLR4) by bacterial lipopolysaccharide (LPS), MSCs polarize to a proinflammatory state (MSC1), characterized by increased production of chemokines and cytokines that may recruit and activate immune effector cells [19]. In a different environment, MSCs may display an anti-inflammatory phenotype (MSC2).

Limited numbers of studies have investigated the immunological properties of equine MSCs [4,20,21,41]. Moreover, there is accumulating evidence that MSCs from different tissue sources differ in their TLR-expression profiles and response to inflammatory stimuli [22]. In this study, we investigated the antibacterial and immunomodulatory properties

\footnotetext{
${ }^{1}$ The Roslin Institute and R(D)SVS, University of Edinburgh, Edinburgh, United Kingdom.

${ }^{2}$ The Euan Macdonald Centre for Motor Neurone Disease Research, University of Edinburgh, Edinburgh, United Kingdom.

*These authors contributed equally to this work.

(C) Yennifer Cortés-Araya et al. 2018; Published by Mary Ann Liebert, Inc. This Open Access article is distributed under the terms of the Creative Commons License (http://creativecommons.org/licenses/by/4.0), which permits unrestricted use, distribution, and reproduction in any medium, provided the original work is properly cited.
} 
of MSCs from three different equine tissues sources, namely, $\mathrm{BM}$ and AT, the two most common sources of clinical MSCs, and endometrium (EM), a promising novel source of therapeutic MSCs [23,24].

\section{Materials and Methods}

\section{Sourcing of MSCS}

BM-MSCs, AT-MSCs, and EM-MSCs were obtained each from three horses as described [5,23], and were characterized following the criteria established by the International Society for Cellular Therapy for MSCs [25]. All animal procedures were carried out according to the UK Home Office Animals (Scientific Procedures) Act 1986 with approval by the Ethical Review Committee, University of Edinburgh.

BM-MSCs were obtained by aspiration of the sternum marrow, centrifugation on a density gradient, and culture of the resulting mononucleated cell layer.

AT-MSCs were obtained by mincing subcutaneous AT followed by collagenase II $(1 \mathrm{mg} / \mathrm{mL}$; Gibco-Thermo Fisher Scientific, Paisley, UK)/bovine serum albumin (BSA; 3.5\%) digestion at $37^{\circ} \mathrm{C}$ under agitation $(100 \mathrm{rpm})$. Digestion was stopped by addition of Dulbecco's modified Eagle's medium (DMEM) 20\% fetal bovine serum (FBS; GibcoThermo Fisher Scientific), the fat layer removed and cells were further washed and seeded.

To harvest EM-MSCs [23], the tissue was washed and minced and then dissociated in DMEM/F-12 containing $0.1 \%$ BSA, $0.5 \%$ collagenase I, $40 \mu \mathrm{g} / \mathrm{mL}$ deoxyribonuclease type I (Sigma-Aldrich, Irvine, UK), and 1\% penicillin/streptomycin (P/S) for $40 \mathrm{~min}$ at $37^{\circ} \mathrm{C}$. Stromal cells were separated by negative selection of epithelial cells using Muc1-beads, filtered, washed, and cultured. MSCs were expanded in DMEM $10 \% \mathrm{FBS}$ and $1 \% \mathrm{P} / \mathrm{S}$ at $37^{\circ} \mathrm{C}$ in a humidified atmosphere containing $5 \%$ carbon dioxide $\left(\mathrm{CO}_{2}\right)$. Alveolar macrophages were obtained by bronchoalveolar lavage from adult horses and cryopreserved as previously described [26]. Before use, cells were thawed and seeded in 24-well plastic plates (Nunc, Thermo Scientific) at $1 \times 10^{6}$ cells $/ \mathrm{mL}$ in complete medium (RPMI-1640 with GlutaMAX ${ }^{\mathrm{TM}}$-I Supplement; Invitrogen), $1 \% \mathrm{P} / \mathrm{S}$ (Invitrogen), and 20\% heat-inactivated horse serum (Sigma-Aldrich) and incubated overnight at $37^{\circ} \mathrm{C}$ and $5 \%$ $\mathrm{CO}_{2}$. The next day, nonadherent cells were removed and the medium was replaced.

\section{Bacterial growth}

Conditioned medium (CM; DMEM 10\% FBS) was harvested from MSCs (BM, EM, and AT; 70,000 cells/well in 12 -well plates) after culture for $16 \mathrm{~h}$ at $37^{\circ} \mathrm{C}$. $\mathrm{CM}$ was spun to remove cell debris and kept at $-80^{\circ} \mathrm{C}$. Escherichia coli ZAP198 was inoculated in BM-CM, EM-CM, and AT-CM for $16 \mathrm{~h}$ at $37^{\circ} \mathrm{C}$, and colony-forming units $(\mathrm{cfu} / \mathrm{mL})$ were obtained by serial dilutions in Luria-Bertani (LB) agar plates. Bacteria grown in DMEM 10\% FBS and LB served as positive controls.

\section{Gene expression analyses}

Total RNA was extracted using Trizol's protocol and was reverse transcribed using Superscript III (18080-044; Invitrogen-Thermo Fisher Scientific). Transcript levels were quantified using an MX3005P quantitative polymerase chain reaction (qPCR) system (Stratagene) with primers listed in Table 1 and SensiFAST SYBR Lo-ROX kit (Bioline). Data were analyzed using Stratagene MxPro software and the messenger RNA (mRNA) levels were determined relative to a standard curve (generated from sample pools) that was run simultaneously.

Results were normalized to $18 \mathrm{~S}$ ribosomal RNA (rRNA) and glyceraldehyde 3-phosphate dehydrogenase (GAPDH), and expressed as arbitrary units (AU). Reverse transcriptasenegative and no template control samples were included in each run as negative controls. For the measurement of colonystimulating factor 1 receptor (CSF1-R) mRNA levels, complementary DNA from equine macrophages and keratinocytes [27] were included as positive and negative controls, respectively.

\section{LPS stimulation experiments}

MSCs at passages 4-6 were seeded at a density of 70,000 cells per well in 12-well plates (Nunc, Thermo Scientific). After $24 \mathrm{~h}$, the cell culture medium was removed and replaced with the medium containing 0 or $0.1 \mu \mathrm{g} / \mathrm{mL}$ LPS (Sigma-Aldrich). After $16 \mathrm{~h}$ of incubation, the wells were washed with phosphate-buffered saline (PBS) and cells harvested into Trizol (Thermo Fisher Scientific), frozen and stored at $-80^{\circ} \mathrm{C}$ before further analysis. Cell stimulation conditions, $0.1 \mu \mathrm{g} / \mathrm{mL}$ LPS for $16 \mathrm{~h}$, were chosen based on results from previous time-course and LPS dose-response

Table 1. Gene and Respective Pair of Primers Used for Quantitative Polymerase Chain Reaction

\begin{tabular}{lllc}
\hline Gene & \multicolumn{1}{c}{ Sense primer sequence $\left(5^{\prime}-3^{\prime}\right)$} & \multicolumn{1}{c}{ Antisense primer sequence $\left(5^{\prime}-3^{\prime}\right)$} & References \\
\hline$I L-6$ & GGACCACTACTCACCACTGC & CCCAGATTGGAAGCATCCGT & \\
$M C P-1$ & ATATCAGGGGGCATTTAGGG & ATTGGCCAAGGAGATCTGTG & \\
$C C L 5$ & CAGTCGTCTTTGTCACCCGA & GGTTCGAGATGCCCTCCAAT & \\
$L C N 2$ & CCACAGCTACAACGTCACCT & GGCTGGGAACTTGGGATGAA & {$[39]$} \\
$I L-8$ & CTTTCTGCAGCTCTGTGTGAAG & GCAGACCTCAGCTCCGTTGAC & {$[28]$} \\
$T L R 4$ & GCCACCTGTCAGATTAGCAAGA & AGAACTGCTATGACAGAAACCATGA & \\
$C S F-1-R$ & GAAATACGTCCGCAGGGACA & GACACGGGTCTCATCTCCAC & \\
$T N F-\alpha$ & CCTGTAGCCCATGTTGTAGCA & GGACCTGGGAGTAGATGAGGT & \\
$I 8 S$ & GCTGGCACCAGACTTG & GGGGATCAGGGTTCG & \\
$G A P D H$ & CAGAACATCATCCCTGCTTC & ATGCCTGCTTCACCACAATTC &
\end{tabular}

CCL5, chemokine ligand-5; CSF1-R, colony-stimulating factor 1 receptor; GAPDH, glyceraldehyde 3-phosphate dehydrogenase; IL-6, interleukin-6; IL-8, interleukin-8; LCN2, lipocalin-2; MCP-1, monocyte chemoattractant protein-1; TLR4, Toll-like receptor 4; TNF- $\alpha$, tumor necrosis factor $\alpha$. 
trials (Supplementary Fig. S1; Supplementary Data are available online at www.liebertpub.com/scd).

\section{Immunocytochemistry}

Cultured cells were washed with PBS and fixed with paraformaldehyde for $15 \mathrm{~min}$, and kept at $4^{\circ} \mathrm{C}$ until use. Cells were permeabilized using methanol:acetone (1:1) followed by incubation with protein blocking solution (Insight Biotechnology). Cells were then incubated with primary antibodies against lipocalin-2 (ab41105; Abcam, Cambridge, UK) or TLR4 (sc-12511; Santa Cruz Biotechnology, Paso Robles, $\mathrm{CA}$ ) for $16 \mathrm{~h}$ at $4{ }^{\circ} \mathrm{C}$, and then with secondary antibodies [antirabbit and anti-goat immunoglobulin G (10042 and 11057; both from Invitrogen-Thermo Fisher Scientific) conjugated to the AF568 fluorochrome]. The primary antibodies have been previously used to detect lipocalin-2 and TLR4 in equine samples $[18,26]$. Samples were then mounted in fluoroshield with 4',6-diamidino-2-phenylindole (DAPI; F6057; Sigma, St Louis, MO) and micrographs taken with a camera connected to a Zeiss Axiovert 25 microscope. The same settings were used for all pictures taken for each antibody. Cells incubated with secondary antibody only were used as negative controls.

\section{Enzyme-linked immunosorbent assay}

Monocyte chemoattractant protein-1 (MCP-1) concentrations in cell culture supernatants were analyzed by enzymelinked immunosorbent assay (ELISA; ELE-MCP-1; Cambridge Bioscience, Cambridge, UK) according to the manufacturer's protocol. In brief, samples and standards were added to a 96well plate coated with anti-equine MCP-1 antibody, and incubated for $2.5 \mathrm{~h}$ at room temperature with gentle agitation. Samples were washed and incubated with biotinylated antibody for $1 \mathrm{~h}$. After addition of horseradish peroxidaseconjugated streptavidin and 3,3,5,5'-tetramethylbenzidine subtract reagent, signal detection was performed at $450 \mathrm{~nm}$. Equine MCP-1 protein provided in the kit was used to produce the standard curve.

\section{Statistical analysis}

The effects of LPS on MSCs from different tissues were analyzed by two-way analysis of variance including "tissue," "treatment," "tissue $\times$ treatment" interaction and "animal" nested within "tissue" using the Minitab 17 statistical software (Minitab, Inc.). Fisher's exact test was used for post hoc comparisons. Data were log-transformed before analyses to comply with normality criteria. Significance was set at $P<0.05$.

\section{Results}

\section{Equine MSCs attenuate bacterial growth and express lipocalin-2}

To assess direct effects of MSCs on bacterial growth, $E$. coli were inoculated in CMs from BM-MSCs, EM-MSCs, and AT-MSCs. All three CMs attenuated bacterial growth, although, on average, EM-MSC and AT-MSC had more pronounced effects than BM-MSC media (Fig. 1A). We then determined whether equine MSCs expressed antimicrobial genes. All cell types expressed lipocalin-2, both at
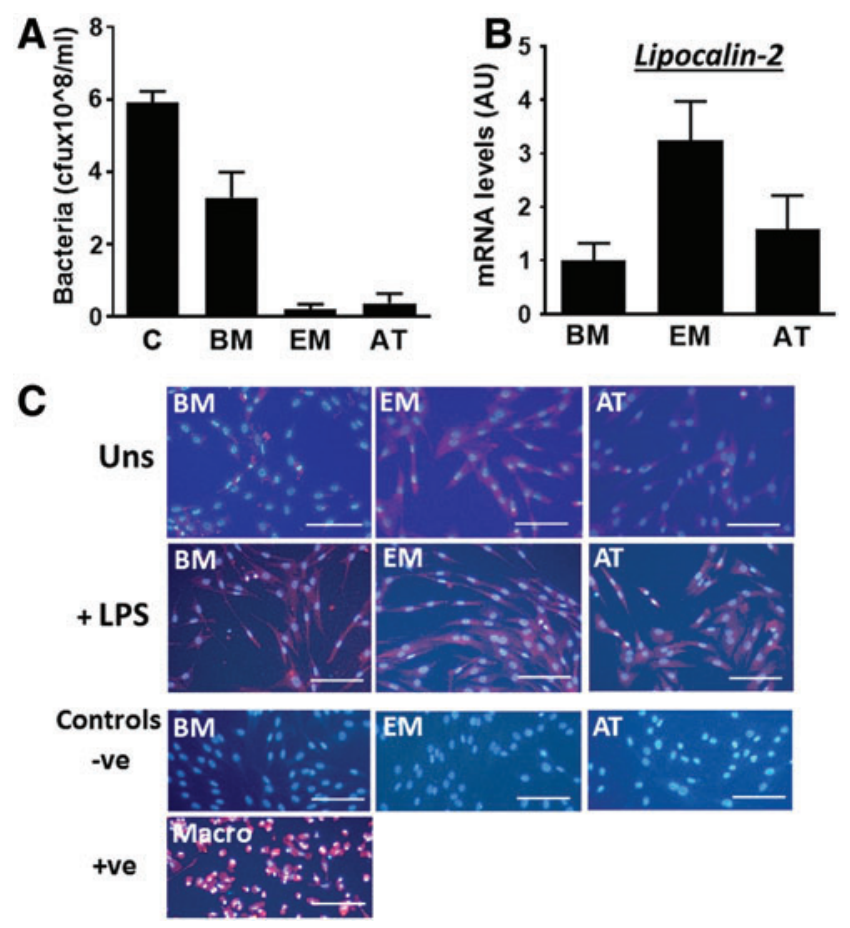

FIG. 1. (A) Escherichia coli growth, indicated as cfu/ $\mathrm{mL}, 16 \mathrm{~h}$ after bacteria inoculation in CMs from BMMSCs, EM-MSCs, or AT-MSCs or in growth medium only (positive control, C). (B) Lipocalin-2 transcript levels in equine MSCs from BM, EM, or AT. Data are given as mean \pm SEM $(n=3$ horses/tissue type). Mean mRNA levels in BM-MSC samples were set to 1. (C) Fluorescence ICC of unstimulated (Uns) or LPS-stimulated MSCs from BM, EM, or AT, with lipocalin-2 antibody. Negative controls (-ve) were produced with LPS-stimulated cells incubated with secondary antibody only, and positive control (+ve) resulted from staining of alveolar macrophages with lipocalin-2 antibody. Lipocalin-2 is indicated by red signal and DAPI-stained nuclei are shown in blue. Pictures were taken in an Axiovert 25 inverted microscope. Scale bars, $100 \mu \mathrm{m}$. AT, adipose tissue; AU, arbitrary units; BM, bone marrow; cfu, colony-forming units; DAPI, 4',6-diamidino2-phenylindole; EM, endometrium; ICC, immunocytochemistry; LPS, lipopolysaccharide; mRNA, messenger RNA; MSCs, mesenchymal stem/stromal cells; SEM, standard error of the mean. Color images available online at www.liebertpub.com/scd

the mRNA (Fig. 1B) and protein (Fig. 1C) levels, but not other antimicrobial genes assayed, namely, LL-37 and $\beta$ defensin 1. Interestingly, EM-MSCs expressed lipocalin-2 at higher mean levels ( $\geq 2$-fold) than BM-MSCs and AT-MSCs (Fig. 1B). Moreover, fluorescence immunocytochemistry (ICC) showed increased lipocalin-2 protein signal in MSCs stimulated with LPS (Fig. 1C).

\section{Equine MSCs express immunomodulatory genes}

To examine the immunomodulatory properties of the three types of MSCs, we determined the expression of genes including the cytokines, MCP-1, chemokine ligand-5 (CCL5), interleukin-6 (IL-6), and IL-8. Samples had detectable levels of all cytokines analyzed (Fig. 2). Mean 

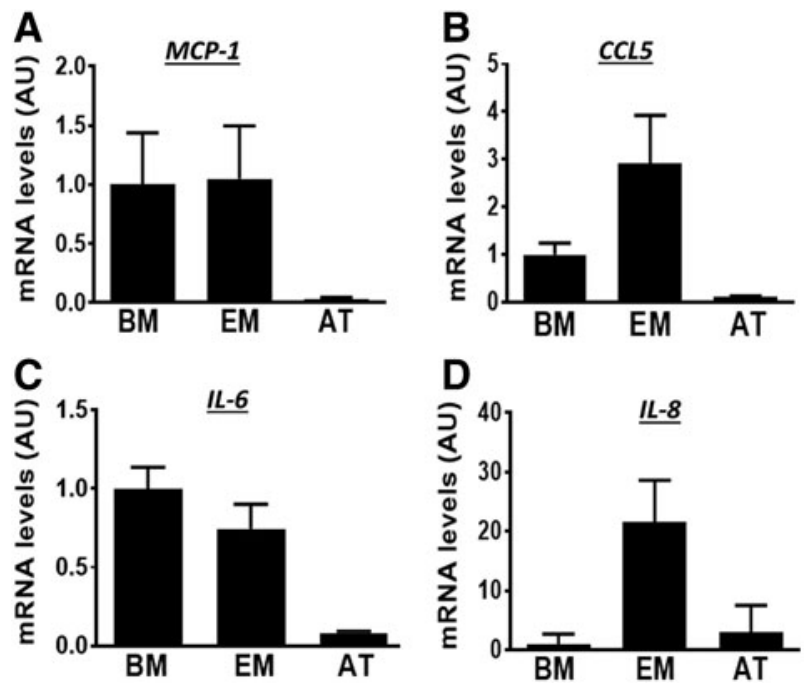

FIG. 2. Transcript levels of (A) MCP-1, (B) CCL5, (C) IL-6, and (D) IL-8 in MSCs from BM, EM, and AT. Data are given as mean $\pm \operatorname{SEM}(n=3$ horses/tissue type). Mean mRNA levels of BM-MSC samples was set to 1. CCL5, chemokine ligand-5; IL-6, interleukin-6; IL-8, interleukin-8; MCP-1, monocyte chemoattractant protein-1.

MCP-1 mRNA levels were higher ( $\geq 2.9$-fold) in BM-MSCs and EM-MSCs than in AT-MSCs (Fig. 2A). Similarly, CCL5 and IL-6 were expressed at relatively much lower levels in AT-MSCs (Fig. 2B, C), whereas mean IL-8 expression was much higher ( $\geq 7$-fold) in EM-MSCs than in either BM-MSCs or AT-MSCs (Fig. 2D). Thus, AT-MSCs expressed the lowest levels of all immunomodulatory genes analyzed.

\section{MSCs are responsive to LPS}

We then examined the effects of stimulation with LPS on the expression of immunomodulatory genes by MSCs. LPS induced a dramatic increase $(\geq 7$-fold; $P<0.05)$ in $\mathrm{MCP}-1$ mRNA levels across all three cell types (Fig. 3A). An increase in CCL5 mRNA was also observed, although this was not significant for any cell type (Fig. 3B). In contrast, for IL6 , a graded response to LPS was observed across cells with lower fold induction in AT-MSCs $(P<0.05)$ than in BMMSCs $(P<0.0001)$ or EM-MSCs $(P<0.001)$ (Fig. 3C, D). A similar graded response in IL-8 mRNA was observed with the LPS induction being significant $(P<0.05)$ only in BMMSCs $(P<0.05)$.

To confirm the results from qPCR, we analyzed MCP-1 levels in CMs using a commercial available ELISA kit that recognizes the equine protein. In agreement with mRNA data (Fig. 3A), MCP-1 protein was significantly induced in response to LPS (Fig. 3E) in BM-MSCs (0.4 \pm 0.07 vs. $1.4 \pm 0.3 \mathrm{ng} / \mathrm{mL}$ for unstimulated and LPS stimulated, respectively, $P<0.05)$, EM $(0.2 \pm 0.03$ vs. $0.9 \pm 0.07, P<0.001)$, and AT $(0.09 \pm 0.02$ vs. $0.3 \pm 0.02, P<0.05)$.

We also quantified the relative expression of TLR4 [28], a cognate LPS receptor, in MSC preparations both at the mRNA (Fig. 4A) and protein (Fig. 4B) levels. TLR4 was detected in unstimulated cells, although at variable levels;

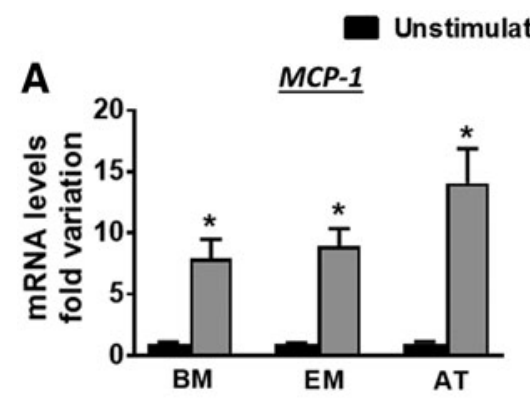

d $\square+$ LPS
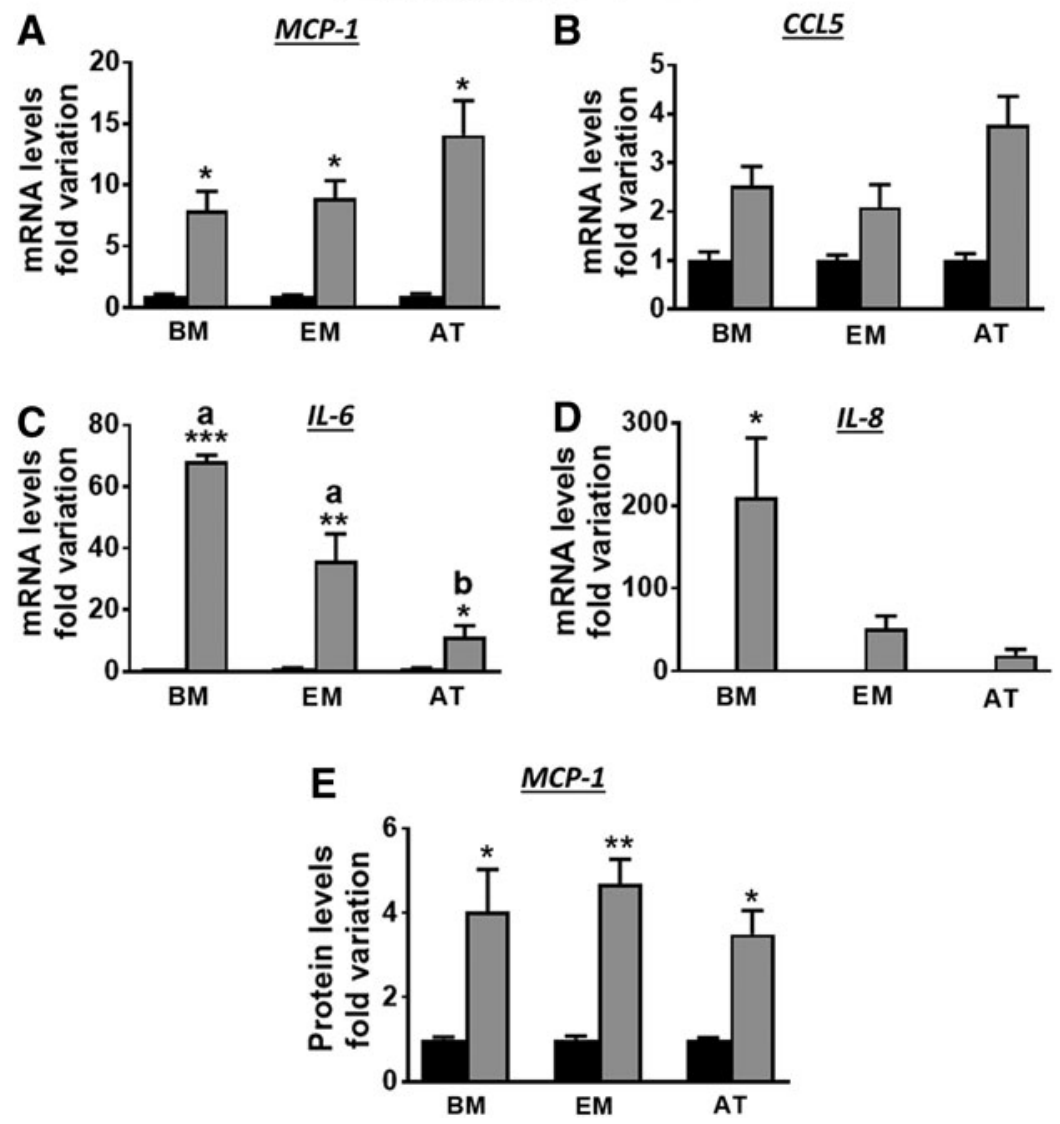

FIG. 3. Fold change in MCP-1 (A), CCL5 (B), IL-6 (C), and IL-8 (D) mRNA levels, and MCP-1 protein levels (E) after LPS stimulation (a gray bars) of MSCs from BM, $\mathrm{EM}$, and AT. In each case, data (given as mean \pm SEM; $n=3$ horses/tissue type) were normalized to mean mRNA levels in unstimulated cells (black bars). ${ }^{*} P<0.05$, $* * P<0.001$, and $* * * P<0.0001$ indicate differences between unstimulated and stimulated cells, whereas different superscripts $(\mathrm{a}, \mathrm{b})$ show significant differences between cell types $(P<0.03)$. 

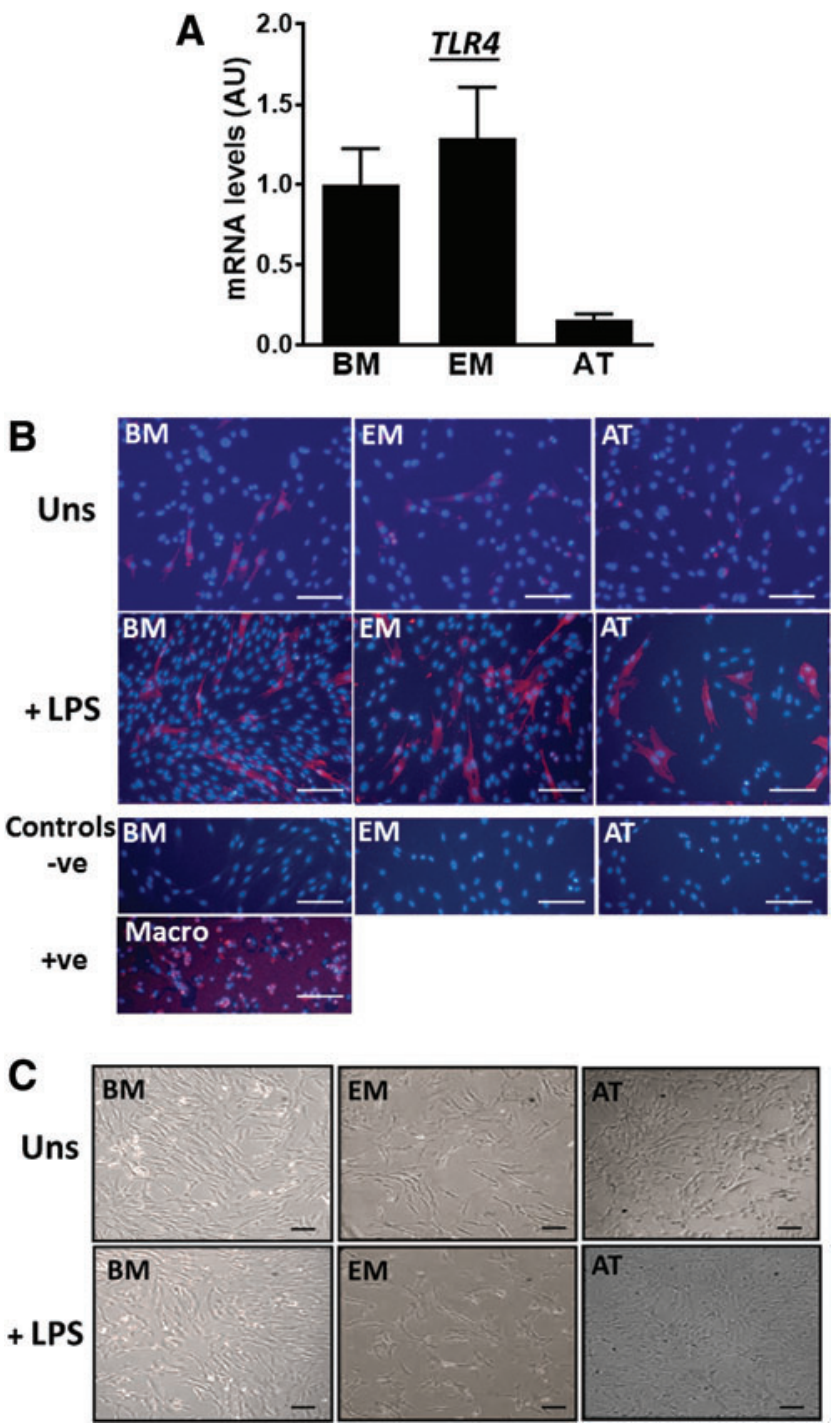

FIG. 4. (A) TLR4 expression measured by qPCR in unstimulated MSCs from BM, EM, and AT. Data are given as mean \pm SEM ( $n=3$ horses/tissue type). Mean mRNA levels in BM-MSC samples were set to 1. (B, C) Photomicrographs showing (B) fluorescence immunostaining of TLR4 (in red) and $(\mathbf{C})$ bright field images of MSCs from BM, EM, and AT before (unstimulated, Uns) and after a $16 \mathrm{~h}$ simulation with LPS $(0.1 \mu \mathrm{g} / \mathrm{mL})$. Negative controls (-ve) correspond to LPS-stimulated cells incubated with secondary antibody only, and positive control (+ve) to alveolar macrophages incubated with TLR4 antibody. All pictures were taken in an Axiovert 25 inverted microscope. Scale bars, $100 \mu \mathrm{m}$. qPCR, quantitative polymerase chain reaction; TLR4, Tolllike receptor 4 . Color images available online at www .liebertpub.com/scd

mean mRNA levels were higher ( $\geq 6.5$-fold) in BM-MSCs and EM-MSCs than those in AT-MSCs (Fig. 4A), consistent with protein data (upper row in Fig. 4B). Cells were then stimulated with LPS for $16 \mathrm{~h}$. This did not produce any apparent changes in cell morphology or cell numbers (Fig. 4C), but results from fluorescence ICC indicated increased levels of TLR4 protein in response to LPS in all MSC types (Fig. 4B).

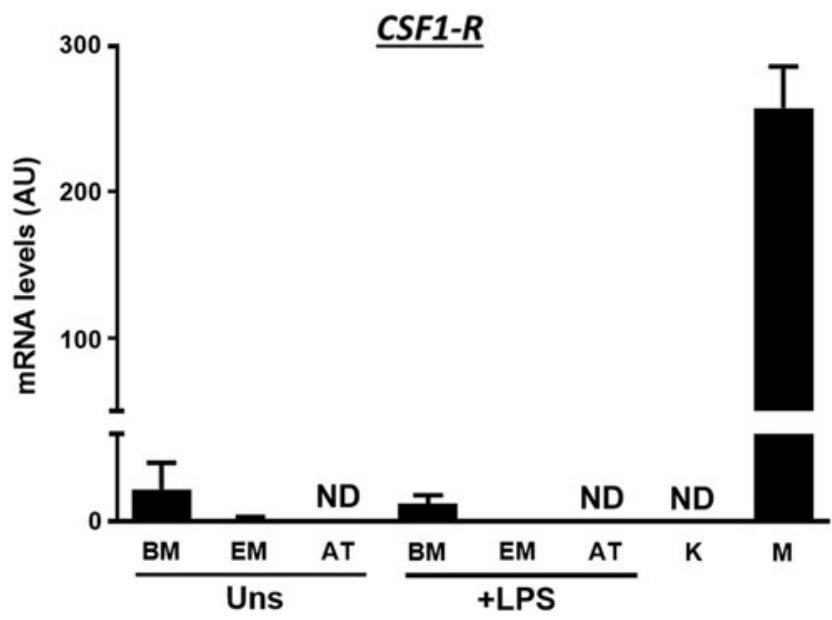

FIG. 5. mRNA levels of the macrophage marker, CSF1-R, in unstimulated (Uns) and LPS-stimulated $(0.1 \mu \mathrm{g} / \mathrm{mL}$ LPS for $16 \mathrm{~h}$ ) MSCs from equine BM, EM, and AT. Keratinocyte $(\mathrm{K})$ and macrophage $(\mathrm{M})$ samples were used as negative and positive controls, respectively. Results are given as mean + SEM. $N=3$ horses per tissue type. CSF1-R, colonystimulating factor 1 receptor; ND, not detected.

\section{Low levels of CSF1-R are present in BM-MSC and EM-MSC preparations}

To assess whether contamination of MSCs with immune cells such as macrophages, as reported in other studies [29], may have influenced our results, we measured the expression of the macrophage-specific gene, CSF1-R, in MSC preparations and compared these with the levels expressed by macrophages (positive control) and keratinocytes (negative control). CSF1-R was detected at very low levels in BM-MSCs and EM-MSCs $(<700$-fold lower than in macrophage samples) but not in AT-MSCs or keratinocytes. Also, LPS stimulation did not induce changes in CSF1-R expression, although this finding did not completely rule out the presence of macrophages in MSC preparations (Fig. 5).

\section{Discussion}

Antimicrobial resistance poses a growing threat for both animal and human health, requiring the identification of novel approaches to fight microbial infection. Studies over the past 10 years have demonstrated the immunomodulatory nature of MSCs including direct antimicrobial effects $[12,13,15,17,18,30-32]$, providing an attractive therapeutic tool alternative or complementary to the use of antibiotics. The identification of novel MSC sources has also represented a step forward in that regard. For example, although BM and AT are well-established sources of clinical MSCs in both humans and animals, EM is now emerging as a promising alternative source with defined cell differentiation and immunomodulatory properties [23,24,30,33]. It is thus critical to compare the immunomodulatory properties of MSCs across different tissues to identify the most optimal source(s) for particular clinical application. In that regard, this is to our knowledge the first study to simultaneously compare the properties of MSCs from $\mathrm{BM}, \mathrm{EM}$, and AT. 
Several studies in humans and rodents [16,34] have shown that MSCs are able to attenuate microbial growth and that this effect can be attributed to the production of antimicrobials. These findings were recently extended for the first time to the horse, specifically to equine blood-derived MSCs [18]. In this study, we report that several common sources of clinical MSCs in the horse are able to inhibit bacterial growth and that this effect varies between cell sources, being apparently higher for EM-MSCs and ATMSCs than for BM-MSCs. Moreover, we show that all three cell sources express lipocalin-2, and that EM-MSCs express, on average, the highest levels.

In agreement with our results, a recent study showed that production of lipocalin-2, among other antimicrobial peptides, contributed to the antibacterial effects of equine blood-derived MSCs that did not produce $\beta$-defensin [18]. In contrast to our results, however, blood-derived MSCs did produce substantial LL-37, a finding that may reflect tissue-specific differences in antimicrobial production by MSCs. In that regard, human BM-MSCs and umbilical cord blood (UCB)-MSCs have been shown to reduce bacterial growth through the secretion of LL37 and $\beta$-defensin 2 , respectively [15,16,34]. Our observation of apparent highest lipocalin-2 expression in EM-MSCs may be linked to the fact that, unlike BM or AT, EM provides a natural body barrier against infection. EM-MSCs could thus provide distinct benefits for clinical use.

In addition to lipocalin-2, equine MSCs from all sources examined expressed the immunomodulatory genes, MCP-1, IL-6, IL-8, and CCL5, suggesting that these cytokines may contribute to the reported ability of equine MSCs to limit infection indirectly by recruiting and activating immune cells $[32,35]$. Of these four cytokines, MCP-1 and CCL5 have to our knowledge not been reported previously to be expressed in equine MSCs. Of interest, expression of all the above immunomodulatory genes was generally reduced in AT-MSCs relative to BM-MSCs and EM-MSCs.

Although we do not have an explanation for this, expression of CSF1-R was lowest in AT-MSCs, suggesting that contamination by macrophages, even at low levels, may have possibly contributed to the elevated cytokine expression in BM and EM. Indeed, the presence of contaminating leukocyte populations in MSC preparations probably contributes to the variability in clinical outcomes reported with the use of these cells. On the contrary, it has also been reported that $\mathrm{BM}$ mesenchymal progenitor cells can originate from $\mathrm{CD} 14^{+}$cells [36]. Overall, this highlights the need for more robust characterization of MSC populations.

In the context of infection and tissue repair, the inflammatory microenvironment and specific pattern of TLR expression in effector cells determine both the interactions between MSCs and immune cells and the outcome of tissue regeneration approaches using MSCs [37]. In agreement with the findings with human BM-MSCs and AT-MSCs [38], and equine UCB-MSCs [20], we detected expression of TLR4 in MSCs from all sources, consistent with their responsiveness to LPS. Polarization into a proinflammatory MSC1 phenotype in response to TLR4 activation is marked by increased secretion of immune effector-recruiting cytokines and chemokines [19]. In this study, in general, the expression of MCP-1, IL-6, IL-8, and CCL5 increased in response to LPS stimulation, consistent with reports with human AT-MSCs and BM-MSCs [39,40] and, for those cytokines that have been examined (IL-6 and IL-8) in equine BM-MSCs [41].

In summary, our results suggest that MSCs from different sources have both antimicrobial activity and constitutively produce lipocalin-2 that may physiologically contribute to innate immune responses, particularly in the case of EMMSCs. However, the largest component of the reported in vivo antibacterial activity of MSCs probably involves indirect activation of immune effector cells. This conclusion is in line with observations that LPS-stimulated human MSCs induce the expression of IL-6 and IL-8 and enhance the activation and phagocytic activity of polymorphonuclear neutrophils [42]. Overall our findings suggest that equine MSCs, particularly EM-MSCs, could be of benefit for reducing and limiting infection. However, further studies will be necessary to assess the antibacterial activity of these cells in an in vivo context so that new strategies can be developed to diversify their use and increase their therapeutic efficiency.

\section{Acknowledgments}

The authors thank Profs. David Gally, David Hume, Scott Pirie and Dr. Anna Karagianni for providing cell samples and giving valuable advice, and Dr. Helen Brown for helping with statistical analysis. This work was supported by awards from the Horserace Betting Levy Board (Prj768 and SPrj022) and the Petplan Charitable Trust (2017-568-606) to C.L.E. and F.X.D. Y.C.-A. was supported by a scholarship from Commission for Science and Technology, Government of Chile (CONICYT). F.X.D. received Institute Strategic Programme Grant funding from The Biotechnology and Biological Sciences Research Council.

\section{Author Disclosure Statement}

The authors declare no competing interests.

\section{References}

1. Burk J, SF Badylak, J Kelly and W Brehm. (2013). Equine cellular therapy-from stall to bench to bedside? Cytometry A 83:103-113.

2. Smith RK, M Korda, GW Blunn and AE Goodship. (2003). Isolation and implantation of autologous equine mesenchymal stem cells from bone marrow into the superficial digital flexor tendon as a potential novel treatment. Equine Vet J 35:99-102.

3. Fortier LA and AJ Travis. (2011). Stem cells in veterinary medicine. Stem Cell Res Ther 2:9.

4. De Schauwer C, K Goossens, S Piepers, MK Hoogewijs, JL Govaere, K Smits, E Meyer, A Van Soom and GR Van de Walle. (2014). Characterization and profiling of immunomodulatory genes of equine mesenchymal stromal cells from non-invasive sources. Stem Cell Res Ther 5:6.

5. Esteves CL, TA Sheldrake, L Dawson, T Menghini, BE Rink, K Amilon, N Khan, B Péault and FX Donadeu. (2017). Equine mesenchymal stromal cells retain a pericyte-like phenotype. Stem Cells Dev 26:964-972.

6. Donadeu F and C Esteves. (2016). Stem cells and equine health. www.eurostemcell.org/factsheet/stem-cells-andequine-health (last acessed November 22, 2016).

7. Esteves CL, TA Sheldrake, SP Mesquita, JJ Pesántez, T Menghini, L Dawson, B Péault and FX Donadeu. (2017). 
Isolation and characterization of equine native MSC populations. Stem Cell Res Ther 8:80.

8. Bussche L and GR Van de Walle. (2014). Peripheral bloodderived mesenchymal stromal cells promote angiogenesis via paracrine stimulation of vascular endothelial growth factor secretion in the equine model. Stem Cells Transl Med 3:1514-1525.

9. Esteves CL and FX Donadeu. (2017). Pericytes and their potential in regenerative medicine across species. Cytometry A 93:50-59.

10. Caplan AI and JE Dennis. (2006). Mesenchymal stem cells as trophic mediators. J Cell Biochem 98:1076-1084.

11. Uccelli A, L Moretta and V Pistoia. (2008). Mesenchymal stem cells in health and disease. Nat Rev Immunol 8:726736.

12. Balan A, G Lucchini, S Schmidt, A Schneider, L Tramsen, S Kuçi, R Meisel, P Bader and T Lehrnbecher. (2014). Mesenchymal stromal cells in the antimicrobial host response of hematopoietic stem cell recipients with graftversus-host disease-friends or foes? Leukemia 28:19411948.

13. Murphy MB, K Moncivais and AI Caplan. (2013). Mesenchymal stem cells: environmentally responsive therapeutics for regenerative medicine. Exp Mol Med 45:e54.

14. Lee JW, X Fang, N Gupta, V Serikov and MA Matthay. (2009). Allogeneic human mesenchymal stem cells for treatment of E. coli endotoxin-induced acute lung injury in the ex vivo perfused human lung. Proc Natl Acad Sci U S A 106:16357-16362.

15. Gupta N, A Krasnodembskaya, M Kapetanaki, M Mouded, X Tan, V Serikov and MA Matthay. (2012). Mesenchymal stem cells enhance survival and bacterial clearance in murine Escherichia coli pneumonia. Thorax 67:533-539.

16. Krasnodembskaya A, Y Song, X Fang, N Gupta, V Serikov, JW Lee and MA Matthay. (2010). Antibacterial effect of human mesenchymal stem cells is mediated in part from secretion of the antimicrobial peptide LL-37. Stem Cells 28:2229-2238.

17. Meisel R, S Brockers, K Heseler, O Degistirici, H Bülle, C Woite, S Stuhlsatz, W Schwippert, M Jäger, et al. (2011). Human but not murine multipotent mesenchymal stromal cells exhibit broad-spectrum antimicrobial effector function mediated by indoleamine 2,3-dioxygenase. Leukemia 25: 648-654.

18. Harman RM, S Yang, MK He and GR Van de Walle. (2017). Antimicrobial peptides secreted by equine mesenchymal stromal cells inhibit the growth of bacteria commonly found in skin wounds. Stem Cell Res Ther 8:157.

19. Waterman RS, SL Tomchuck, SL Henkle and AM Betancourt. (2010). A new mesenchymal stem cell (MSC) paradigm: polarization into a pro-inflammatory MSC1 or an Immunosuppressive MSC2 phenotype. PLoS One 5:e10088.

20. Tessier L, D Bienzle, LB Williams and TG Koch. (2015). Phenotypic and immunomodulatory properties of equine cord blood-derived mesenchymal stromal cells. PLoS One 10:e0122954.

21. de Mattos Carvalho A, AL Alves, MA Golim, A Moroz, CA Hussni, PG de Oliveira and E Deffune. (2009). Isolation and immunophenotypic characterization of mesenchymal stem cells derived from equine species adipose tissue. Vet Immunol Immunopathol 132:303-306.

22. Raicevic G, M Najar, B Stamatopoulos, C De Bruyn, N Meuleman, D Bron, M Toungouz and L Lagneaux. (2011).
The source of human mesenchymal stromal cells influences their TLR profile as well as their functional properties. Cell Immunol 270:207-216.

23. Rink BE, KR Amilon, CL Esteves, HM French, E Watson, C Aurich and FX Donadeu. (2017). Isolation and characterization of equine endometrial mesenchymal stromal cells. Stem Cell Res Ther 8:166.

24. Cabezas J, D Rojas, F Navarrete, R Ortiz, G Rivera, F Saravia, L Rodriguez-Alvarez and FO Castro. (2018). Equine mesenchymal stem cells derived from endometrial or adipose tissue share significant biological properties, but have distinctive pattern of surface markers and migration. Theriogenology 106:93-102.

25. Dominici M, K Le Blanc, I Mueller, I Slaper-Cortenbach, F Marini, D Krause, R Deans, A Keating, DJ Prockop and E Horwitz. (2006). Minimal criteria for defining multipotent mesenchymal stromal cells. The International Society for Cellular Therapy position statement. Cytotherapy 8:315317.

26. Karagianni AE, R Kapetanovic, BC McGorum, DA Hume and SR Pirie. (2013). The equine alveolar macrophage: functional and phenotypic comparisons with peritoneal macrophages. Vet Immunol Immunopathol 155:219-228.

27. Sharma R, MR Livesey, DJ Wyllie, C Proudfoot, CB Whitelaw, DC Hay and FX Donadeu. (2014). Generation of functional neurons from feeder-free, keratinocyte-derived equine induced pluripotent stem cells. Stem Cells Dev 23: 1524-1534.

28. Yuan ZQ, EA Gault, P Gobeil, C Nixon, MS Campo and L Nasir. (2008). Establishment and characterization of equine fibroblast cell lines transformed in vivo and in vitro by BPV-1: model systems for equine sarcoids. Virology 373: 352-361.

29. Radcliffe CH, MJ Flaminio and LA Fortier. (2010). Temporal analysis of equine bone marrow aspirate during establishment of putative mesenchymal progenitor cell populations. Stem Cells Dev 19:269-282.

30. Gargett CE, KE Schwab and JA Deane. (2016). Endometrial stem/progenitor cells: the first 10 years. Hum Reprod Update 22:137-163.

31. Shi Y, J Su, AI Roberts, P Shou, AB Rabson and G Ren. (2012). How mesenchymal stem cells interact with tissue immune responses. Trends Immunol 33:136-143.

32. Krasnodembskaya A, G Samarani, Y Song, H Zhuo, X Su, JW Lee, N Gupta, M Petrini and MA Matthay. (2012). Human mesenchymal stem cells reduce mortality and bacteremia in gram-negative sepsis in mice in part by enhancing the phagocytic activity of blood monocytes. Am J Physiol Lung Cell Mol Physiol 302:L1003-L1013.

33. Rink E, B Teresa, H French, E Watson, C Aurich and FX Donadeu. (2018). The fate of autologous endometrial mesenchymal stromal cells after application in the healthy equine uterus. Stem Cells Dev 27:1046-1052.

34. Sung DK, YS Chang, SI Sung, HS Yoo, SY Ahn and WS Park. (2016). Antibacterial effect of mesenchymal stem cells against Escherichia coli is mediated by secretion of beta-defensin-2 via toll-like receptor 4 signalling. Cell Microbiol 18:424-436.

35. Hall SR, K Tsoyi, B Ith, RF Padera, JA Lederer, Z Wang, X Liu and MA Perrella. (2013). Mesenchymal stromal cells improve survival during sepsis in the absence of heme oxygenase-1: the importance of neutrophils. Stem Cells 31: 397-407. 
36. Hackett CH, MJ Flaminio and LA Fortier. (2011). Analysis of CD14 expression levels in putative mesenchymal progenitor cells isolated from equine bone marrow. Stem Cells Dev 20:721-735.

37. Najar M, M Krayem, N Meuleman, D Bron and L Lagneaux. (2017). Mesenchymal stromal cells and toll-like receptor priming: a critical review. Immune Netw 17:89-102.

38. Hwa Cho H, YC Bae and JS Jung. (2006). Role of toll-like receptors on human adipose-derived stromal cells. Stem Cells 24:2744-2752.

39. Liu GY, Y Liu, Y Lu, YR Qin, GH Di, YH Lei, HX Liu, YQ Li, C Wu, XW Hu and HF Duan. (2016). Short-term memory of danger signals or environmental stimuli in mesenchymal stem cells: implications for therapeutic potential. Cell Mol Immunol 13:369-378.

40. Kim SH, A Das, JC Chai, B Binas, MR Choi, KS Park, YS Lee, KH Jung and YG Chai. (2016). Transcriptome sequencing wide functional analysis of human mesenchymal stem cells in response to TLR4 ligand. Sci Rep 6:30311.

41. Vézina Audette R, A Lavoie-Lamoureux, JP Lavoie and S Laverty. (2013). Inflammatory stimuli differentially modulate the transcription of paracrine signaling molecules of equine bone marrow multipotent mesenchymal stromal cells. Osteoarthritis Cartilage 21:1116-1124.

42. Brandau S, M Jakob, K Bruderek, F Bootz, B Giebel, S Radtke, K Mauel, M Jäger, SB Flohé and S Lang. (2014). Mesenchymal stem cells augment the anti-bacterial activity of neutrophil granulocytes. PLoS One 9:e106903.

Address correspondence to: Dr. Cristina L. Esteves The Roslin Institute and R(D)SVS University of Edinburgh Easter Bush, Midlothian Edinburgh EH25 9RG Scotland United Kingdom

E-mail: cristina.esteves@roslin.ed.ac.uk

Received for publication November 14, 2017 Accepted after revision July 24, 2018

Prepublished on Liebert Instant Online July 25, 2018 